\title{
Coronary-Cameral Fistula and Coronary Ectasia as a Prelude to Ischemia in the Absence of Obstructive Disease-A Case Report
}

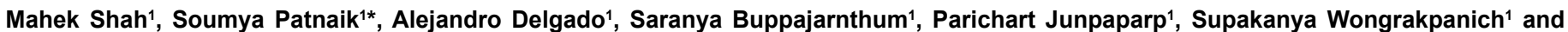 Vincent M. Figueredo ${ }^{2}$}

${ }^{1}$ Department of Medicine, Einstein Medical Center, Philadelphia, PA 19141, USA

${ }^{2}$ Division of Cardiology, Einstein Medical Center, Philadelphia, PA 19141, USA

\begin{abstract}
A coronary artery fistula is a communication between a coronary artery and a chamber of the heart (coronarycameral fistula). Coronary ectasia is the luminal dilatation of the adjacent normal segment, believed to be a form of atherosclerotic process, and is reported in about 3-8\% of patients undergoing coronary angiogram. Coronarycameral fistula and coronary ectasia, when existing concurrently, may present as a prelude to ischemia even in the absence of obstructive disease. We report here one such case seen in an elderly female. She presented with recurrent episodes of angina despite the absence of occlusive coronary artery disease. We also review the literature.
\end{abstract}

Keywords: Coronary artery fistula; Coronary ectasia; Recurrent angina

\section{Introduction}

A coronary artery fistula is a communication between a coronary artery and a chamber of the heart (coronary-cameral fistula) or a segment of the systemic or pulmonary circulation (coronary arteriovenous fistula). Coronary artery fistulae account for $0.4 \%$ of congenital cardiac anomalies [1]. Coronary ectasia (CAE) defined as $1.5-2$ fold luminal dilatation of the adjacent normal segment, believed to be a form of atherosclerotic process is reported in about $3-8 \%$ of patients undergoing coronary angiogram; may present alone or in combination with obstructive stenotic lesions [2]. Imaging modalities that can assist in the diagnosis of a coronary fistula include echocardiography, cardiac catheterization and multi-detector row computed tomography $[3,4]$. We present a patient with a left anterior descending artery to left ventricle fistula who presented with recurrent episodes of angina, despite the absence of occlusive coronary artery disease. In this context, we review the literature.

\section{Case Report}

An 83-year-old female with a history of hypertension and radioiodine treated Graves disease presented to the emergency department with epigastric pain and shortness of breath of 1 week duration. She denied any cardiac history or having similar symptoms in the past. Her vital signs were normal at the time of presentation. Her electrocardiogram showed sinus rhythm with a right bundle branch block that was unchanged from prior. Her troponin level was elevated at $4.75 \mathrm{ng} / \mathrm{dl}$, with a peak of $5.22 \mathrm{ng} / \mathrm{dl}$. A transthoracic echocardiogram showed isolated grade II diastolic dysfunction with normal systolic function and no wall motion abnormalities (Figure 1).

A coronary angiography showed a severely ectatic left main coronary artery that divided into left anterior descending (LAD) and left circumflex arteries. There was no evidence of occlusive disease. The LAD was severely ectatic and tortuous with two moderate sized diagonal branches. A severe distal LAD to left ventricular fistula (coronary-cameral fistula) was noted. The left circumflex artery was also found to be significantly tortuous and ectatic and gave out a large obtuse marginal and posterior descending artery. Her right coronary artery was non-dominant, regular in size with a small posterolateral artery. The distal portion of the small posterior left ventricular branch had a small fistulous connection with the left ventricle. As her symptoms were self-limited, she was discharged on medical therapy (Figure 2).

Eighteen months later, she returned to the emergency department with typical anginal pain, shortness of breath and a troponin level of $1.28 \mathrm{ng} / \mathrm{dl}$. She denied any fever, undue exertion or emotional stress preceding the episode. Her symptoms resolved within hours of presentation. A discussion regarding an increased likelihood of developing myocardial ischemia and infarction due to an abnormal underlying coronary anatomy was undertaken with the patient. The risks and benefits of surgical versus catheter closure of the fistula were also discussed with the patient but she chose medical management.

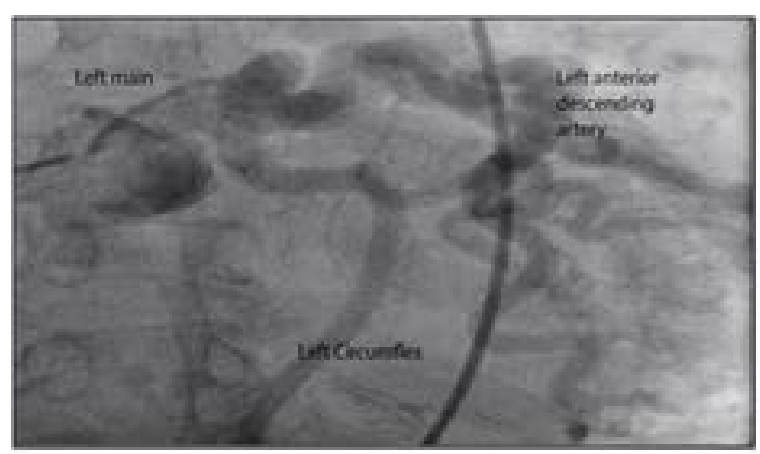

Figure 1: Left coronary arteriogram in right anterior oblique view at 30 degrees with caudal 15 degrees showing tortuous and dilated coronary arteries.

*Corresponding author: Soumya Patnaik, Albert Einstein Medical Center, 5501 Old York Road, Klein 363, Philadelphia 19141, USA, Tel: 215-421-7388; E-mail: patnaiks@einstein.edu; pat_soumya@yahoo.in

Received September 20, 2015; Accepted October 13, 2015; Published October 20, 2015

Citation: Shah M, Patnaik S, Delgado A, Buppajarnthum S, Junpaparp P, et al (2015) Coronary-Cameral Fistula and Coronary Ectasia as a Prelude to Ischemia in the Absence of Obstructive Disease-A Case Report. J Cardiovasc Dis Diagn 3: 227. doi:10.4172/2329-9517.1000227

Copyright: ( 2015 Shah M, et al. This is an open-access article distributed under the terms of the Creative Commons Attribution License, which permits unrestricted use, distribution, and reproduction in any medium, provided the original author and source are credited. 


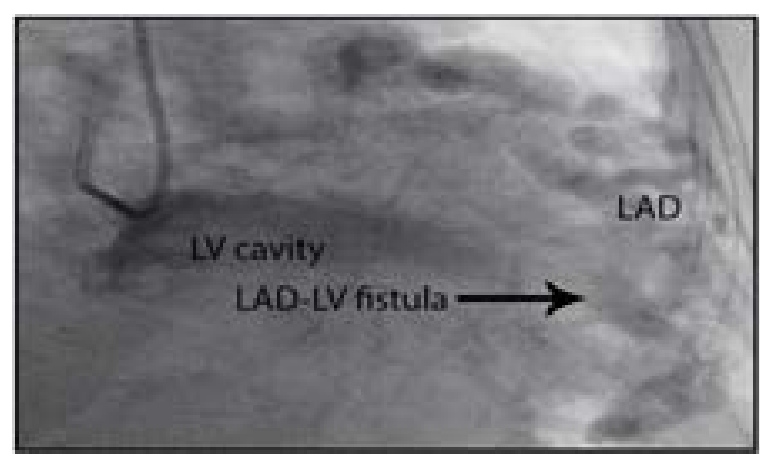

Figure 2: Magnified view of the above image showing Left anterior descending artery-left ventricular fistula.

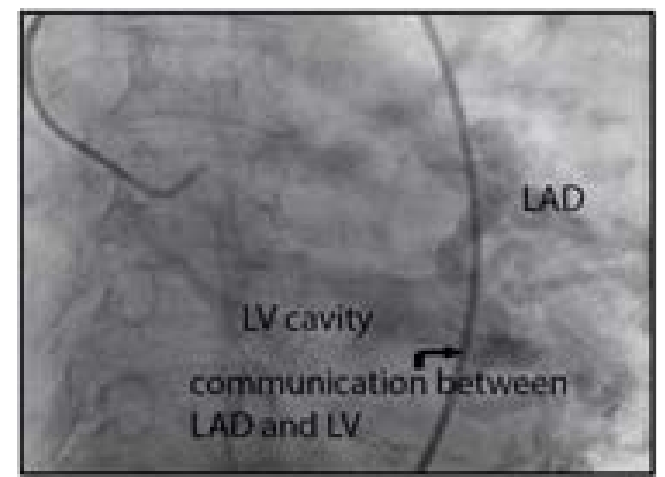

Figure 3: Antero-posterior view showing the communication between the left anterior descending artery and left ventricle.

Twelve months following the last episode of severe angina, she returned to the hospital with persistent palpitations and an elevated troponin level of $1.61 \mathrm{ng} / \mathrm{dl}$. Her heart rate was elevated to the 120 beats per minute and an electrocardiogram confirmed sinus tachycardia. Her echocardiogram was unchanged compared to previous. She denied indulging in unaccustomed exercise, fever or emotional stress. On further enquiry, it was noted she had recently started exogenous thyroid supplements over the counter. Her TSH level was found to be low at $0.09 \mathrm{mcIU} / \mathrm{ml}(\mathrm{N}=0.35$ to $4.94 \mathrm{mcIU} / \mathrm{ml})$ with a normal free T4. Her hormonal replacement was discontinued and her tachycardia improved with resolution of symptoms. She refused to consent for CT, MRI or a repeat coronary angiogram. She continues to be followed closely in the outpatient setting and has been asymptomatic for over 5 months (Figure 3 ).

\section{Discussion}

Coronary fistulae may be congenital or acquired as in cases with a history of cardiac or coronary interventions. Congenital coronary fistulae can be seen younger populations often are incidental findings. It is rare for this anomaly to be discovered in patients over 80 years of age for the first time. Most coronary artery fistulae are small and do not cause symptoms. A majority of these fistulae resolve spontaneously or are incidentally discovered. However, larger fistulae ( $>3$ times normal vessel size) may be associated with symptoms and complications [5]. Fistulae can be associated with myocardial ischemia, heart failure from volume overload, premature atherosclerosis, endocarditis and valvular disorders. Such fistulae become increasingly symptomatic with age and can result in progressive atherosclerosis, coronary ectasia and aneurysm development [5-7]. Patients with symptomatic coronary fistulae usually present with dyspnea on exertion, increased fatigability, signs of high-output congestive heart failure, palpitations and rarely angina [8]. high-output congestive heart failure, palpitations and rarely angina.Our patient presented with breathlessness and elevated troponins and showed large coronary artery fistula on angiogram. Such presentation at an age of 83 years has never been reported before (Figure 4).

The impact of coronary artery fistula and coronary artery ectasia on myocardial ischemia independently and in combination are not fully understood. The presence of ectatic coronary vessels can accompany a large coronary artery fistula with high blood flow secondary to changes that develop in the involved arteries over time. The coronary vessel attempts to compensate by progressive enlargement of the ostia and feeding artery. The mechanism that may lead to recurrent ischemia is the phenomenon of coronary steal through the involved vessel, but this remains controversial [9]. This mechanism may be due to the diastolic pressure gradient and diversion of blood flow from the coronary vasculature to a lower pressure receiving cavity as the left ventricle in our patient. Ectatic coronary vasculature may further lead to increased turbulence and low flow reserve within the coronaries that is exacerbated during stress, thus precipitating ischemia [10]. Since larger fistulae tend to dilate over time, there is a progressively increasing risk of thrombosis, endocarditis and other complications. There is no consensus about the management of coronary ectasias or fistulae. Large fistulae are to be closed irrespective of symptoms; while small to moderate sized fistulae are closed if there is evidence for myocardial ischemia, arrhythmias, ventricular dysfunction, ventricular enlargement or endarteritis [11].

Surgical closure had been the only strategy until percutaneous methods were introduced in 1983. Avoiding surgery is appealing to the patients and In absence of clear guidelines the closure technique is decided mostly on the size, anatomy and the local expertise [12,13].

Asymptomatic patients may be followed up at regular intervals with imaging. Patients with large fistulae, unfavourable anatomy or multiple connections may be considered for surgery over percutaneous techniques [14-16]. A high procedural complication rate with advancing age and the irreversible nature of coronary ectasia can make the decision regarding choice of therapy rather challenging due to the lack of adequate research regarding this topic. Most of the evidence regarding procedural closure for significant coronary fistulae comes from single center studies and case series [17]. Medical therapy may be implemented instead and is aimed at symptom control. Use of anticoagulants for CAE is controversial and lacks evidence. It is also

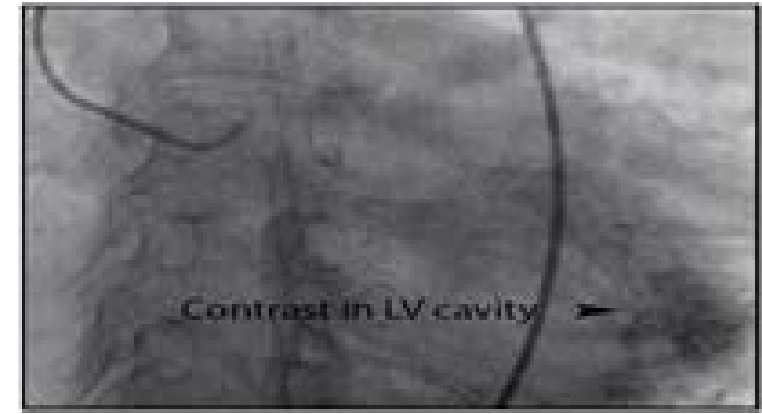

Figure 4: Appearance of contrast within the left ventricular cavity after injection of contrast material into the left coronary artery. 
Citation: Shah M, Patnaik S, Delgado A, Buppajarnthum S, Junpaparp P, et al. (2015) Coronary-Cameral Fistula and Coronary Ectasia as a Prelude to Ischemia in the Absence of Obstructive Disease-A Case Report. J Cardiovasc Dis Diagn 3: 227. doi:10.4172/2329-9517.1000227

Page 3 of 3

believed by some physicians that ectasia may worsen by use of nitrates which are not used in our patient. In presence of obstructive lesions in association it is logical to offer conventional risk-reduction measures and established medical therapies like anti-platelet drugs and statins.

\section{Conclusion}

When large coronary fistula is associated with ectasia there is high chance of myocardial ischemia. Large fistulae can progressively dilate over time with increased risk of thrombosis, endocarditis and further ischemia. Hence they need closure as soon as detected or close surveillance if left uncorrected. Coronary ectasia with associated fistulae may be of varied mechanisms and such cases are managed on case to case basis. Larger registries are necessary to better characterize the outcomes and decide the appropriate management strategy in such patients.

\section{References}

1. Schamroth C (2009) Coronary artery fistula. J Am Coll Cardiol 53: 523.

2. Mavrogeni S (2009) Coronary artery ectasia: diagnosis and treatment. E-Journal of the ESC council for cardiology practice 51: 158-163

3. Chen ML, Lo HS, Su HY, Chao IM (2009) Coronary artery fistula: assessment with multidetector computed tomography and stress myocardial single photon emission computed tomography. Clin Nucl Med 34: 96-98.

4. Ma ES, Yang ZG, Guo YK, Zhang XC, Sun JY, et al. (2008) Clinical value of 64-slice CT angiography in detecting coronary artery anomalies. Sichuan Da Xue Xue Bao Yi Xue Ban 39: 996-999.

5. Saglam H, Koçogullari CU, Kaya E, Emmiler M (2008) Congenital coronary artery fistula as a cause of angina pectoris. Turk Kardiyol Dern Ars 36: 552-554.

6. Padfield GJ (2009) A case of coronary cameral fistula. Eur J Echocardiogr Jep049.
7. Vavuranakis M, Bush CA, Boudoulas $\mathrm{H}$ (1995) Coronary artery fistulas in adults incidence, angiographic characteristics, natural history. Cathet Cardiovasc Diagn 35: 116-120.

8. Said SA, Lam J, van der Werf T (2006) Solitary coronary artery fistulas: a congenital anomaly in children and adults: a contemporary review. Congenit Heart Dis 1: 63-76.

9. Bruce (1989) Myocardial infarction due to multiple coronary-ventricular fistulas Catheterization and Cardiovascular Diag 16: 247-249.

10. Manginas (2006) Coronary artery ectasias: imaging, functional assessment and clinical implications. Eur Heart J 27: 1026-1031.

11. Warnes CA, Williams RG, Bashore TM (2008) Guidelines for the Management of Adults with Congenital Heart Disease: Executive Summary: a report of the American College of Cardiology/American Heart Association Task Force on Practice Guidelines (writing committee to develop guidelines for the management of adults with congenital heart disease)

12. Reidy JF, Sowton E, Ross DN (1983) Transcatheter occlusion of coronary to bronchial anastomosis by detachable balloon combined with coronary angioplasty at same procedure. Br Heart J 49: 284-287.

13. Challoumas D, Pericleous A, Dimitrakaki IA, Danelatos C , Dimitrakaki G et al (2014) Coronary arteriovenous fistulae: a review. Int J Angiol 23: 1-10.

14. Said SA, el Gamal MI, van der Werf T (1997) Coronary arteriovenous fistulas: collective review and management of six new cases--changing etiology, presentation, and treatment strategy. Clin Cardiol 20: 748-752.

15. Urrutia SCO, Falaschi G, Ott DA, Cooley DA (1983) Surgical management of 56 patients with congenital coronary artery fistulas. Ann Thorac Surg 35: 300307.

16. Trehan V, Yusuf J, Mukhopadhyay S (2004) Transcatheter closure of coronary artery fistulas. Indian Heart J 56:132-139.

17. Reidy JF, Tynan MJ, Qureshi S (1990) Embolisation of a complex coronary arteriovenous fistula in a 6 year old child: the need for specialised embolisation techniques. Br Heart J 63: 246-248. 